\title{
Las otras radios: El complejo escenario de la radio en el Perú
}

\author{
Carlos Rivadeneyra Olcese (Universidad de Lima) \\ Recibido: 11/12/08 \\ Aprobado: 18/01/09
}

\begin{abstract}
RESUMEN: La radio peruana revela una enorme diversidad en proporción directa a su multiculturalidad, la misma que muestra un proceso lleno de influencias de diversos actores sociales lo que ha producido un escenario complejo y sumamente rico, además lleno de oportunidades y retos. Más allá de la gran radio comercial capitalina están las otras radios, pequeñas empresas, provincianas, de la iglesia o de los alcaldes o de micro empresarios hijos de la melomanía folklórica, diversos actores apasionados por establecer un medio de comunicación. Las motivaciones múltiples producen un escenario con muchos tipos de radio que deseamos comenzar a conocer.
\end{abstract}

Palabras clave: Radio - radio comunitaria - radio educativa - radio pública diversidad cultural.

\section{The other radios: Alternative scenario in Peru}

SuMMARY: Peruvian radio shows a huge diversity in direct proportion to its multiculturality, the same which shows a process full of different influences of social actor which have produced a complex and extremely rich scenario, that is also filled with opportunities and challenges. Beyond the great capital commercial radio are the other radios, small companies, provincial, from church or the mayor or small business owners sons of folkloric melomania, different actors with a passion to establish a new media. The multiple motivations produce a scenario with many types of radio that we wishes to start knowing.

Key worlds: Radio - community radio - educational radio - public radio - cultural diversity. 


\section{Introducción}

E n el Perú, el medio de comunicación masivo más extendido es la radio. Según cifras del Ministerio de Transportes y Comunicaciones (MTC) a diciembre del 2007 existían 2.236 autorizaciones vigentes de estaciones de radio, ${ }^{1}$ su evolución ha sido rápida en los últimos 25 años (véase el gráfico). El incremento del número de estaciones de radio se debe a varios factores: los cada vez más veloces cambios tecnológicos que han hecho posible el abaratamiento de los equipos para la radiodifusión y para la producción de programas radiales; las políticas liberales, que han promovido el establecimiento de estaciones de radio de carácter comercial; y la gran diversidad de emprendimientos que van desde los sociales, como las comunidades campesinas y nativas (indígenas), los organizaciones no gubernamentales de desarrollo (comúnmente conocidos como ONG) laicos y de la Iglesia (católica y evangélica) las diversas congregaciones y denominaciones, los grupos de vecinos y migrantes en diversas ciudades y los em-

Evolución de la cantidad de emisoras de radio

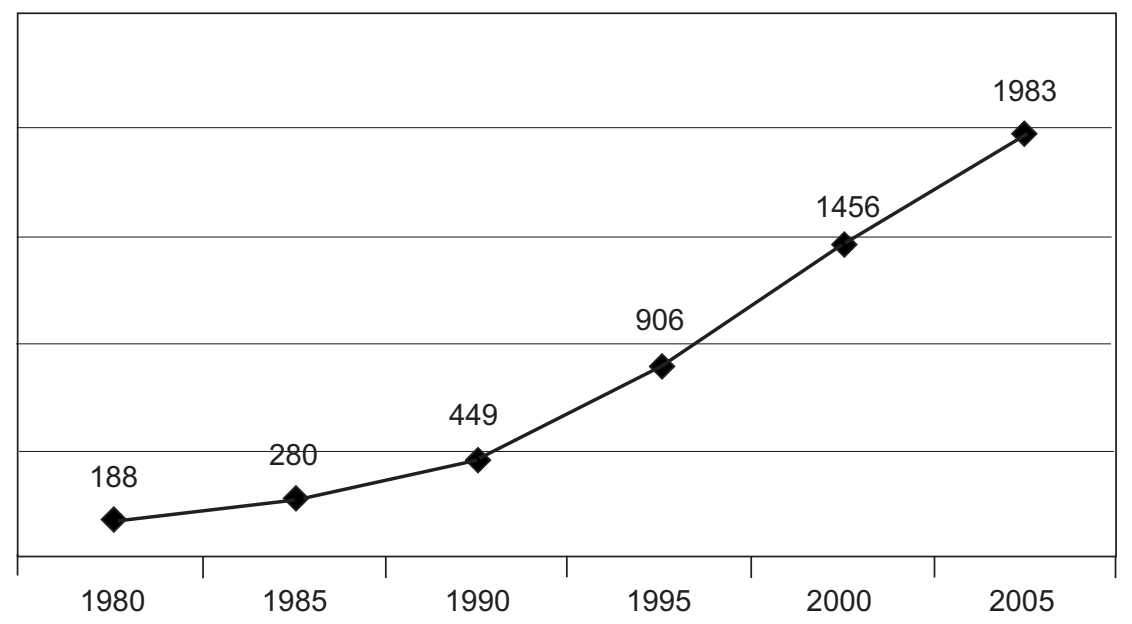

1 Según el informe de Estadísticas de los Servicios de Radiodifusión y Servicios Privados a nivel nacional, elaborado por la Dirección General de Regulación y Asuntos Internacionales de Comunicaciones del Ministerio de Transportes y Comunicaciones, diciembre de 2007. Véase <http://www.mtc.gob.pe/implementacion/comunicacion/politicas/estadisticas/ ARCA_boletin.pdf $>$. La Televisión también logra un gran crecimiento, tal como lo muestra el documento en mención, llegando a 1.036 con autorización vigente, poco más de la mitad de la cantidad de estaciones de radio. 
prendimientos estatales, que no se quedan en el formal Instituto de Radio y Televisión del Perú (IRTP), sino que tienen rostro local o provincial con las emisoras promovidas por municipios de diverso ámbito, hasta emisoras (o retransmisoras) de varios proyectos del Estado. Esta gran cantidad de actores en la radio peruana representan a la vez a la gran diversidad sociocultural de Perú, todos con una alta necesidad de expresión.

La inmensa mayoría de estaciones de radio en nuestro país corresponden a empresas privadas de diversas y complejas características, algunas grandes empresas y conglomerados y otras medianas, pequeñas y hasta microempresas de carácter familiar. Una pequeña parte, menor a la décima porción, son estaciones de radio con autorizaciones de tipo educativo. A pesar de que la Ley de Radio y Televisión (Ley 28278) vigente desde julio del 2004 reconoce hasta tres modalidades de radios: comerciales, educativas y comunitarias. ${ }^{2}$ De esta última tipología no existe a la fecha ninguna estación reconocida de manera formal. Pero lo más sorprendente de la clasificación que plantea la ley en mención es que no define un tipo de medio de comunicación de carácter público o en su defecto estatal.

Fruto del estudio de la radio peruana en los últimos 15 años, en los que gracias a numerosos viajes y visitas (a ciudades, provincias, distritos, caseríos y comunidades campesinas y nativas) hemos podido observar el fenomenal proceso de la radio en nuestro país, entregamos las siguientes líneas con el afán de comprender la complejidad de las radioemisoras que

2 La Ley de Radio y Televisión las define así: “Artículo 9.- Por su finalidad. Los servicios de radiodifusión, en razón de los fines que persiguen y del contenido de su programación, se clasifican en:

a) Servicios de Radiodifusión Comercial: Son aquellos cuya programación está destinada al entretenimiento y recreación del público, así como a abordar temas informativos, noticiosos y de orientación a la comunidad, dentro del marco de los fines y principios que orientan el servicio.

b) Servicios de Radiodifusión Educativa: Son aquellos cuya programación está destinada predominantemente al fomento de la educación, la cultura y el deporte, así como la formación integral de las personas. En sus códigos de ética incluyen los principios y fines de la educación peruana.

Las entidades educativas públicas, sólo pueden prestar el servicio de radiodifusión educativa.

c) Radiodifusión Comunitaria: Es aquella cuyas estaciones están ubicadas en comunidades campesinas, nativas e indígenas, áreas rurales o de preferente interés social. Su programación está destinada principalmente a fomentar la identidad y costumbres de la comunidad en la que se presta el servicio, fortaleciendo la integración nacional". 
no pertenecen a los consorcios o grupos empresariales basados en la capital, sino más bien a las experiencias que emergen desde el interior del país o la periferia de las ciudades. En buena cuenta, a esas estaciones de radio que muchas veces se les llama "las otras radios", y que configuran un escenario diferente y alternativo a la industria de la radio comercial.

\section{A falta de una definición}

Una de las características de las otras radios es que no cuentan con una definición clara y sintética, debido a que sus objetivos van más allá de ser simples empresas comerciales, ${ }^{3}$ por ende, no son emisoras que solo buscan alcanzar una gran audiencia o una imagen de marca radial de fácil recordación o una gran cobertura geográfica; tampoco se caracterizan por tener ofertas de contenidos estandarizados ${ }^{4}$ y programaciones de formatos cerrados, sino que estamos frente a un gran, diverso y complejo grupo de experiencias radiales con características multiformes que intentaremos presentar, acercándonos poco a poco a este rico escenario.
Los investigadores ingleses Lewis $y$ Booth $^{5}$ han señalado que en el mundo los modelos de radio históricamente establecidos son tres: comercial, público y comunitario, propuesta que incluye el ausente modelo de medio público que la Ley de Radio y Televisión peruana no toma en cuenta, sin duda un elemento fundamental para entender el sistema de medios ${ }^{6}$ de un país. La radiodifusión de propiedad privada y fines comerciales es la radio financiada fundamentalmente por la publicidad, cuyo objetivo final es obtener beneficios económicos, como afirman los ingleses,

\section{[...] la necesidad de maximizar au- diencias y conseguir economías de es- cala obliga a los operadores comercia- les a agruparse para la realización de programas y formación de redes.}

La radio pública tiene una diversidad de experiencias en el ámbito mundial; sin embargo, podemos decir que es un modelo en el que la propiedad de los medios es estatal, y, por ello de todos los ciudadanos de un país, pero su gestión tiene diferentes matices. Existen países donde la ges-

3 Con afán de lucro y búsqueda de utilidades económicas.

4 La mayoría de emisoras comerciales que han establecido grupos o consorcios de empresas radiales ofrecen desde Lima -y vía satélite "para todo el país"- ofertas programáticas basadas en música o información noticiosa.

5 LEWIS, P. M. y J. BOOTH. El medio invisible. Radio pública, privada, comercial y comunitaria. Barcelona: Paidós, 1992.

6 Llamamos sistema de medios a las reglas explícitas y tácitas que cada país pone en práctica y que definen las principales características del escenario de los medios masivos de comunicación. 
tión de los medios públicos, y en este caso la radio, está a cargo del gobierno de turno que nombra incluso a los directores responsables de su administración. Esto se da en la mayoría de experiencias. También hay países, sobre todo en Europa, donde los directorios que manejan las estaciones de radio pública tienen amplia participación ciudadana, presencia de organizaciones de la sociedad civil y cierto grado de autonomía. De más está decir que las experiencias con mayor participación de la ciudadanía y sus organizaciones están más cerca de lo que podríamos llamar una radio de gestión pública, un modelo que fortalece la democracia desde la comunicación, en los países donde se practica.

Si seguimos la propuesta de los investigadores Lewis y Booth, nos encontraremos con más de un problema para definir las radios comunitarias, debido a la diversidad de enfoques que tiene este tipo de experiencias en el mundo. Con el fin de ser cautelosos al abordar este complejo escenario, afirmaremos que las emisoras comunitarias entienden

[...] a sus oyentes como sujetos y como participantes [...] no tienen objetivos lucrativos y generalmente intentan diversificar su financiación para evitar la dependencia de cualquiera de sus fuentes de ingresos.?
Lo curioso es que los tres modelos propuestos por los ingleses están presentes en las otras radios, es decir que en el Perú existe una reapropiación particular de los modelos de radio mundialmente conocidos. En un intento por presentarlos de la manera más sencilla posible, definiremos ciertas variables que nos ayudarán a observar sus principales características.

\section{La diversidad de las otras radios}

Con el fin de no extraviarnos en la complejidad, se tomarán en cuenta las siguientes variables:

- Tipo o nombre por el cual se le puede o suele reconocer.

- Ubicación geográfica.

Propiedad de la emisora.

- Objetivos que persigue y cómo se han definido.

- Gestión de la emisora.

- Contenidos, que se desprenden de sus objetivos y su estrategia comunicativa, y se expresa en su oferta programática.

- Cobertura de la estación de radio.

- Participación de la población a la que atienden o modalidades de participación social en la emisora.

- Estatus legal (¿cuentan o no con autorización del MTC?).

7 LEWIS, P. M. y J. BOOTH. Op. cit., pp. 34-35. 


\section{Radio comercial provinciana: Los empresarios de los cuatro suyos}

Si bien los grupos y consorcios empresariales, ${ }^{8}$ lo que hemos llamado la industria de la radio, son los emprendimientos más notorios de la radiodifusión sonora, no son el único modelo de empresa comercial en la radio peruana. A lo largo y ancho del país se encuentra una gran diversidad de experiencias de empresas de carácter comercial que dan vida a un multicolor escenario radiofónico. Como hemos afirmado líneas arriba, la gran mayoría de las radios en el Perú son de carácter comercial y la mayoría son, asimismo, empresas medianas, pequeñas y hasta unipersonales, expresión del empresariado provinciano.

En muchos distritos del país se encuentran emisoras de radio que son propiedad de pequeños empresarios locales (muchos de ellos microempresarios), que, por diferentes razones, emprendieron la gestión de una emisora radial. Por ejemplo, se encuentran microbroadcasters muy aficionados a un tipo de música determinada, que, como en un momento no encontraban dicho género musical en la oferta de las emisoras regionales o nacionales, decidieron establecer una emisora de radio que tuviera como fin, desde un inicio, la difusión musical. Incluso en Lima, en el cono norte, la emisora Santa Apolonia transmite 24 horas de música del departamento de Cajamarca.

Existen también emisoras comerciales de empresas que han intentado convertirse en medianas o grandes empresas -la mayoría en AM-, que en algún momento de su historia lograron renombre en importantes ciudades del país. Entre estas figuran, por ejemplo, Radio Libertad en Trujillo, Radio Nevada y Radio Melodía en Arequipa, y Radio Tacna y Radio Piura en las ciudades del mismo nombre; sin embrago, el gran reto que han afrontado -y que en varios casos lo siguen haciendo- es su sostenibilidad.

En cuanto a su programación, esta se caracteriza por combinar espacios musicales e informativos con revistas de opinión y entretenimiento, con el acento propio de lo regional y lo local y con un verdadero reconocimiento de la audiencia. No obstante, sus costos de producción resultan elevados si se comparan con los presupuestos publicitarios que logran en sus respectivas regiones y ciudades, y cada día les resulta más difícil competir con emisoras pertenecientes a la industria de la

8 Nos estamos refiriendo a las empresas de radiodifusión como Corporación Radial del Perú y el Grupo RPP, y a otras empresas comerciales más pequeñas que se agrupan con las primeras en el Comité de Radio. Véanse detalles en http://www.comitederadio. com.pe/ 
radio que transmite desde Lima. Esta última repite su señal en decenas de ciudades del país, con lo cual logra una audiencia que les permite alcanzar presupuestos publicitarios más altos que los que logra una sola emisora de una provincia.

Algunas emisoras comerciales regionales se han visto obligadas a concesionar ciertos espacios radiales a terceros, no siempre productores radiales, a cambio de un monto mensual (incluso diario) de dinero como alquiler del espacio. En algunos casos, la crisis por no contar con suficiente publicidad, ha obligado a estas emisoras a dejar de estructurar y ofrecer una programación determinada y convertirse en difusores de varios programas inconexos con diversos y hasta antagónicos objetivos, en la mayoría de los casos de bajo presupuesto de producción $y$, por ende, de baja calidad radiofónica.

Si bien el mecanismo de concesión de espacios radiales permite la subsistencia de la emisora, también tiene colaterales como el deterioro de la calidad de su oferta radiofónica, con la consiguiente pérdida de audiencia, oyentes que migran hacia estaciones musicales locales o emisoras de la industria, incluso existen algunos casos en los que las antaño emisoras regionales se han convertido en repetidoras de la industria de la radio que trans- mite desde la capital. Una consecuencia positiva de la concesión de espacios radiales es que permite la visibilización mediática de actores sociales, no todos comerciales, que de otra forma no accederían a los medios de comunicación. Nos referimos a grupos de migrantes que producen sus programas con la música y tradiciones de sus lugares de origen, ONG con componentes de difusión y comunicación masiva, asociaciones culturales, vecinales y hasta gobiernos locales.

A contrapelo de este deterioro de las medianas empresas de radio regional han aparecido y lo siguen haciendo emisoras más pequeñas y hasta localizadas en ciertas zonas de las grandes ciudades del interior del país, emisoras en FM que han retomado los objetivos de hacer una radio regional con información, opinión y participación en actividades sociales y culturales locales y regionales.

Algunos casos de la segunda generación de emisoras comerciales regionales y locales en FM tienen ciertas dificultades y hasta problemas para lograr sus permisos y licencias formales; no pocas han vivido algún tiempo sin contar con la licencia formal respectiva, pero sí con una licencia social, es decir con la aprobación de la población convertida en su audiencia y en su sostén social. 
La voz del Perú profundo: Las radios de comunidades campesinas y nativas

En el Perú existen 5.818 comunidades campesinas y nativas, ${ }^{9}$ pero con relación a ese número y al total de emisoras formalmente establecidas, podemos afirmar que muy pocas comunidades indígenas han emprendido la gestión de emisoras de radio. Aunque existen algunos casos de emisoras que llevan el nombre de comunidades campesinas de la costa o la sierra, o de comunidades nativas de la selva, muy pocas son respuesta del genuino esfuerzo de sus comuneros miembros. A pesar de ser escasos los ejemplos que podemos reseñar sobre este tipo de emisoras, su importancia es enorme pues representan propuestas de grupos de base sobre cuya vigencia social, política y económica se discute mucho en la actualidad y que mediante la comunicación masiva dan a conocer el proceso sociocultural por el que atraviesan.

Las emisoras de las comunidades campesinas y nativas están ubicadas en poblados rurales, distritos rurales y de forma excepcional en las capitales de provincia, son de propiedad de las comunidades adecuadamente organizadas que cuentan con directivas democráticamente elegidas. Estas emisoras tienen como objetivo ser un órgano de expresión de los miembros de la comunidad para contribuir a la comunicación interna entre sus miembros y facilitar las relaciones con otros actores sociales del escenario rural, como municipios, gobierno regional, iglesia y empresas que trabajan en su territorio.

El manejo de este tipo de emisoras está dado por la misma comunidad; muchas veces la gestión de la radio es responsabilidad de la directiva de la comunidad; en otras se forma un comité especial para dicha labor, aunque en ciertos casos existen alianzas con la Iglesia, el municipio o alguna ONG que asesora el manejo de la emisora y ayuda a su sostenibilidad. Su contenido está sustancialmente basado en la difusión cultural; gran parte de su programación está dedicada a la difusión de música campesina de artistas no profesionales y de artistas populares profesionales que cultivan una gran diversidad de géneros musicales tradicionales, y, en general, costumbres propias de la comunidad. Este tipo de emisoras tiene claro su rol de reivindicación cultural.

Las emisoras de las comunidades campesinas y nativas se ubican en su gran mayoría en FM; son de baja potencia y cobertura geográfica bastante limitada; cubren las localidades rurales del ámbito de la comunidad y algunas ni siquiera satisfacen a todo el

9 Ministerio de Agricultura. Directorio de Comunidades Campesinas. PETT, 2002. 
territorio comunal. Cuentan con la participación de los miembros de la comunidad, desde niños hasta adultos mayores, pero con poca capacitación formal para hacer radio con estándares de calidad, es decir que utilizan la radio como medio de expresión; muchos de los responsables de los programas o emisoras no han recibido capacitación formal alguna para hacer su trabajo radial y logran productos radiales que, ante el juicio académico o la escucha de algún poblador urbano acostumbrado a las emisoras comerciales, podrían ser catalogados como "de mala calidad", y es que la estética de estas emisoras es muy diferente y está lejos de la estandarización, del manejo de géneros y de los formatos radiofónicos de los productores profesionales de la radio. Esta diferencia representa también una riqueza aún poco estudiada.

Muchas de las emisoras de comunidades campesinas o nativas tienen vida efímera, ya que su sostenimiento requiere no solo de entusiasmo, sino también de recursos económicos, lo que es un tema complicado, teniendo en cuenta que la población rural a la que sirve se encuentra en pobreza (según cifras oficiales alcanza a dos de cada cinco pobladores peruanos). Uno de los ejemplos más importante es el de Radio Quispillacta, ubicado en Huamanga, capital de la región Ayacucho, emisora que transmite en la frecuencia 1120 AM, de propiedad de la comunidad campesina del mismo nombre, esta emisora cuenta con dos bloques de transmisión: de 4 a 8 de la mañana y de 5 a 9 de la noche, en los que se ofrece una programación que combina contenidos informativos y música campesina, siendo toda su programación en idioma quechua. Radio Quispillacta logró el premio de Comunicación Rural 2001 otorgado por el Programa Intergubernamental de Desarrollo de las Comunicaciones (PIDC) de la Unesco, en reconocimiento a su trabajo en favor del uso de su lengua original, el quechua, y por su apoyo a diversas campañas de comunicación en beneficio del desarrollo social de la población campesina ayacuchana, región donde su población rural alcanza el 42 por ciento, de la cual el 85 por ciento es quechuahablante y el 27 por ciento ${ }^{10}$ aún es analfabeta.

Además, existen emisoras menos conocidas y reconocidas, más pequeñas y de ámbito de acción más restringido, como el caso también ayacuchano de Chaski Radio del distrito de Vischongo, en la provincia de Vilcashuamán. Esta emisora que nació bajo el impulso de un pequeño grupo de comuneros, rápidamente se ha con-

10 Según cifras del XI Censo Nacional de Población, INEI, 2007. 
vertido en la radio que acompaña a la comunidad y al distrito del mismo nombre, al tener una programación básicamente musical con escasos momentos informativos pero que revalora su medio ambiente, tradición y cultura. Así, por ejemplo, varios de sus programas han tomado el nombre de diversas especies de la fauna de la zona, de sus restos arqueológicos o de los géneros musicales tradicionales. En esta emisora, diversos actores de la comunidad y el distrito están presentes; así, niños de educación primaria y sus profesores producen un programa semanal que logra gran audiencia en las familias. Los jóvenes de educación secundaria producen programas diarios, por las tardes, en su mayoría musicales con los artistas de éxito de la comunidad, es decir con artistas diferentes de aquellos de las emisoras urbanas. Las instituciones, desde el municipio, la gobernación, la posta médica hasta los diversos programas sociales, están en la emisora produciendo programas radiales o participando de los existentes, pues entienden el medio como el instrumento de mejor llegada a la población distrital y comunal.

Si bien podemos narrar muchas experiencias, cada una con sus pro- pias características, algo que unifica a este tipo de emisoras de las comunidades indígenas peruanas es la gran cantidad de dificultades que deben sortear para acceder a su formalidad. Si bien, como reseñamos líneas arriba, la Ley de Radio y Televisión vigente desde 2004 contempla la modalidad de radiodifusión comunitaria como mecanismo de expresión de la sociedad rural, el Ministerio de Transportes y Comunicacianes (MTC) no ha logrado facilitar mecanismos para formalizar este tipo de experiencias; los trámites se hacen en la capital, en español y no en idiomas tradicionales, $\mathrm{y}$, por último, los estudios técnicos ${ }^{11}$ para establecer servicios de radiodifusión no están terminados ni actualizados por parte del MTC, limitando de esta forma la provisión de permisos y licencias formales a este tipo de emprendimientos comunicacionales.

\section{Del púlpito al dial: La Iglesia en la radio}

Para nadie es un secreto que la Iglesia -católica y evangélica- tiene un trabajo mediático importante y aún más interesante. La radio es el medio de comunicación en el Perú (y en varios países de Latinoamérica) en el que la Iglesia

11 Nos referimos principalmente a la actualización del Plan Nacional de Asignación de Frecuencias, documento con el cual el MTC orienta y aprueba la entrega de autorizaciones. Sin la existencia de dicho estudio el MTC ni siquiera inicia el trámite que culminará con la entrega de permisos formales a las radioestaciones. 
está presente en muchas capitales de regiones y de provincias. En el Perú, la Iglesia católica ha establecido emisoras de radio de reconocido prestigio y renombre. Nos referimos, por ejemplo, a Radio Santa Rosa o Radio María, que transmiten en Lima la primera y la segunda en varias capitales de regiones del país; Radio La Voz de la Selva de Iquitos; Radio Onda Azul de Puno; Radio Oriente de Yurimaguas, entre otras. La Iglesia evangélica también cuenta con varias emisoras, como el Ministerio La Luz y la Iglesia Ebenezer $\mathrm{y}$, con otras denominaciones, poseen decenas de estaciones de radio en diversas zonas del país.

Los objetivos de la Iglesia para el establecimiento de estaciones de radio son diversos, pero en general fundan estos medios de comunicación para "llevar la palabra del Señor" y lo hacen de varias formas. Hay emisoras que son religiosas, algunas las llaman eclesiales por su contenido portador del discurso oficial de una Iglesia determinada; trabajan programas a partir de las Sagradas Escrituras; algunas rezan el rosario y transmiten la misa o un culto evangélico. Existe también un grupo amplio de emisoras de iglesias que tienen como objetivo evangeli$z a r$, meta que aún no definen con precisión ni consenso, algunas emisoras de la Iglesia católica evangelizan "enseñando la palabra del Señor" y producen programas muy cercanos al discurso oficial, tradicional y hasta conservador de la Iglesia católica, pero hay otras emisoras que han logrado reconocimiento al convertirse en instrumento de representación de los sectores populares y excluidos de la sociedad; algunas de estas emisoras se hacen llamar "radios ciudadanas", porque defienden los derechos ciudadanos de la población. Estas emisoras defensoras de los principios democráticos buscan representar a los sectores sociales pobres e "invisibles" para las políticas de desarrollo social de los gobiernos de turno; para ello se valen de estrategias de participación en muchos casos con muy buenos resultados. Destacan en este grupo las emisoras de la congregación de Santo Domingo (dominicos), que gestionan Radio Quillabamba en la provincia del mismo nombre en Cusco, Radio Madre de Dios en la región del mismo nombre, Radio Santo Domingo en Chimbote, Radio San Martín en Arequipa, entre otras.

Algunas de estas emisoras se autodefinen como "radios populares" o "educativas". La primera característica data de los años de su creación, en la década de 1970, cuando jugaron un papel importante para el movimiento popular campesino, sindical o barrial y sus demandas reivindicativas. Otras se definen a sí mismas como "educativas", porque sus acciones y objetivos están dirigidos al sector educativo $\mathrm{y}$ usan la difusión radial como herramienta de trabajo. Respecto de sus objetivos se podrían mencionar por lo menos tres particularidades: apoyo a 
la educación formal, muy exitosa en la década de 1970, que, a pesar del tiempo transcurrido, continúa vigente en procesos de alfabetización y facilita la culminación de los estudios primarios, como ocurre con el Instituto Radiofónico Fe y Alegría (IRFA). ${ }^{12}$ Este, a pesar de no contar con emisoras, utiliza la señal de estaciones de radio de la iglesia católica.

Una segunda particularidad de las radios educativas desde la iglesia, se manifiesta en la atención a una población determinada, de acuerdo con su ubicación geográfica o su interés temático, no necesariamente eclesial. Destacan en esta modalidad Radio San Sebastián en Chepén, La Libertad, y Radio Emmanuel de Huaycán, en la zona este de Lima.

La tercera peculiaridad de radios educativas corresponde a lo que líneas arriba hemos denominado "radios ciudadanas", un modelo asumido -entre otras- por emisoras de la Iglesia que defienden principios democráticos como los derechos humanos. Al respecto, uno de los mejores ejemplos es el citado por el Informe Final de la Comisión de la Verdad y Reconciliación (CVR), que señala que entre 1981 y 1992 Radio Onda Azul de
Puno logró consolidar un equipo profesional comprometido con los más pobres, que en aquel entonces vivían entre "dos fuegos", según testimonio de su director, citado en el informe de la CVR:

La iglesia contaba con Radio Onda Azul. Cuando sucedía un hecho de violencia en un lugar, salía el equipo de la Vicaría y Onda Azul salía en el mismo carro o en otro, pero ambos estaban en el lugar. Generalmente siempre había un abogado, un sacerdote o religiosa y un periodista. El medio de comunicación hablaba del tema todos los días. ${ }^{13}$

Un trabajo de comunicación popular, democrático y participativo en uno de los momentos más difíciles de nuestro país en el siglo $\mathrm{XX}$, fue asumido por emisoras de radio vinculadas a la Iglesia católica, que demostró su compromiso con la defensa de la vida, desde una posición en defensa de los derechos humanos.

Por último, debemos señalar que desde el punto de vista legal, en general, estas emisoras de radio cuentan con licencia de funcionamiento $y$, en su mayoría, están adecuadamente equipadas con una infraestructura de

12 IRFA tiene en Ecuador y Venezuela estrategias de educación desde la radio y cuentan, en ambos países, con decenas de emisoras.

13 Tomado del Informe Final de la CVR. Tomo III, capítulo 3: Las organizaciones sociales [en línea]. <http://www.cverdad.org.pe/ifinal/index.phpque>. 
sonido y radiodifusión que les permite cubrir gran parte de la geografía de una región o departamento de Perú.

\section{Emisoras radiales de ONG}

Las ONG también tienen un trabajo radial interesante, si bien son pocas las que tienen licencias de estaciones de radio -muchas de las que existen están vinculadas a congregaciones de la Iglesia católica-, existen experiencias en las que estas organizaciones promueven las emisoras con el fin de que sean grupos sociales de base los que en mediano plazo se hagan cargo de dichas estaciones, ese es el caso del Centro de Educación y Comunicación ILLA, institución que ha promovido emisoras en Ica, Puno y Piura, y que luego de tres años de asistencia técnica y capacitación entrega las estaciones para que sean manejadas por grupos sociales de base.

En su mayoría las ONG promueven y colaboran con el establecimiento de emisoras comunitarias rurales y urbano-marginales, como es el caso del Centro de Comunicación y Promoción del Desarrollo de Villa El Salvador (Cecoprodeves), que promueve Radio Stereo Villa, en el cono sur de Lima.

Dentro de las congregaciones religiosas católicas que promueven emisoras de radio está la del Sagrado Corazón, la orden jesuita, que mediante sus organismos de desarrollo promueve la comunicación y el desarro- llo social en diversas regiones del país, como es el caso de Radio Cutivalú de Piura y Radio Marañón en la región nororiente, así como otros en los departamentos de Cajamarca y Amazonas. Estas han sido interesantes y exitosas experiencias de radio que promueven el desarrollo social desde la discusión de propuestas de desarrollo inclusivo hasta el tratamiento detallado de temas específicos, como la salud, la participación y la vigilancia ciudadana de la gestión pública, la equidad de género y la defensa ambiental, entre otros.

Estas emisoras, promovidas o gestionadas por ONG, cuentan con licencia de carácter educativo y cumplen con un destacable rol de promoción del desarrollo social, apostando por la libertad de expresión como derecho fundamental.

\section{Radios municipales (o del alcalde)}

No existen cifras exactas pero en muchos distritos de nuestro país funcionan emisoras de radio que sirven fundamentalmente como instrumento de difusión y propaganda de la gestión edil; al respecto, existen por lo menos tres interpretaciones posibles. La primera vinculada a la necesidad del gobierno local o provincial de informar sobre su gestión y de convocar a los vecinos a participar de las actividades que organiza el municipio. En muy pocos casos estas emisoras abren sus puertas a organizaciones sociales, 
tratan temas más allá de la gestión edil o abordan la participación social como posibilidad no solo de vigilancia sino también de gobierno participativo. La segunda interpretación está basada en las mismas declaraciones de algunos alcaldes, ${ }^{14}$ quienes señalan que es su obligación brindar entretenimiento a la población y, por eso retransmiten emisoras de radio musicales e informativas de la capital. Por último, están las emisoras que con cínico descaro funcionan como instrumento propagandístico, muchas veces reeleccionista del alcalde de turno, quien, de no cumplir su objetivo de extender su gestión política, "se llevará" la radio para hacer oposición y crítica, desde fuera del municipio, a la nueva gestión edil. A esto, en buena cuenta, le podemos llamar "radio de alcalde". A pesar de este panorama existen algunas experiencias positivas, como la de Radio Diplomat del municipio provincial de San Ignacio (en la región Cajamarca), la misma que se hace llamar la primera radio agroecológica del nororiente y que efectivamente realiza un trabajo educativo a favor y en defensa del medio ambiente y los recursos naturales.

Muchas de estas emisoras -la mayoría-, no cuentan con licencia ni formal, ni social, pero el poder local o provincial las dota de una seudoinmunidad.
En nuestro país, contrariamente de lo que existe en otros, como España, no se cuenta con una modalidad de radiodifusión municipal que tenga como objetivo discutir y plantear soluciones a la problemática local, tomando en cuenta las propuestas de diversos grupos sociales, lo que representa un lamentable vacío legal que ha sido llenado en la práctica por la compleja realidad antes descrita.

\section{Radios estatales: CPACC y Programa Nacional de Cuencas Hidrográficas y Conservación de Suelos (Pronamachcs)}

Si bien las radios de los municipios (y no de los alcaldes de turno) podrían ser consideradas radios estatales, como hemos explicado antes, se deben en la mayoría de los casos a intereses particulares. De otro lado, en el Perú existen experiencias de radiodifusión que han sido promovidas desde el gobierno central.

Nos referimos, en primer lugar, al Conglomerado de Proyectos de Apoyo a la Comunicación Comunal, CPACC, que existió como PACC entre 1994 y el 2007.

Este conglomerado ha instalado 1.580 sistemas de televisión de los cuales 350 incluyen también radio FM, según detalla la web del MTC.

14 Que prefieren guardar anonimato. 
La propuesta del CPACC define su apoyo a la comunicación comunal a partir de dotar de estaciones de repetición de la señal de la radio y televisión estatales en poblados rurales, con el fin de "lograr su integración al país", en palabras del ingeniero Carlos Schaeffer, coordinador técnico del CPACC. Los contenidos que reciben las poblaciones rurales -e indígenas en un alto porcentaje- mediante el sistema de repetidoras del CPACC, corresponden a la programación que elabora y emite desde Lima el Instituto de Radio y Televisión del Perú, IRTP, es decir que no se promueve la comunicación inter-comunal, provincial o regional, sino que más bien se recibe información desde la capital del país.

Lo insólito de las emisoras repetidoras del CPACC es su estado de ilegalidad, debido a que siendo el MTC la institución encargada de otorgar permisos, autorizaciones y licencias para el uso del espectro radioeléctrico, no puede tener autorización alguna, lo cual quiere decir que el ministerio instaló durante más de una década 1.580 emisoras re-transmisoras sin tener licencia. Felizmente este hecho se está subsanando desde el 2007, al haberse iniciado el proceso de entrega de dichas estaciones a los gobiernos regionales.
Otro caso es el del Ministerio de Agricultura, que desde 1993 a través del Proyecto de Fomento de la Transferencia de Tecnología a las Comunidades Campesinas de la Sierra (Proyecto FEAS), ${ }^{15}$ creó las radios campesinas como una respuesta a la necesidad de contar con un medio de comunicación masivo que contribuya con el desarrollo rural; de esta manera, dicho proyecto instaló ocho emisoras en seis regiones del país.

Las radioemisoras fueron ubicadas inicialmente en las localidades de Ayabaca y Huancabamba, en el departamento de Piura; Cajamarca y Jaén en el departamento de Cajamarca; Omate en el departamento de Moquegua; Tarata en Tacna y Ayaviri y Juli en Puno.

Lo curioso de este interesante proyecto es que, a la fecha, de las ocho emisoras o radios campesinas en funcionamiento solo una de ellas utiliza una frecuencia con autorización a nombre del Instituto de Radio y Televisión del Perú, a pesar de que su oferta programática es diferente de la del IRTP. Las siete restantes salen al aire hace más de quince años sin contar con la autorización respectiva, y en los últimos ocho años bajo la responsabilidad del Pronamachcs.

15 Tomado de Estadísticas de los Servicios de Radiodifusión y Servicios Privados a Nivel Nacional, elaborado por la Dirección General de de Regulación y Asuntos Internacionales de Comunicaciones, Información a Diciembre de 2007. En http://www.mtc.gob.pe/implementacion/comunicacion/politicas/estadisticas/estadisticas.htm 
Respecto de estas dos iniciativas estatales para efectuar comunicación masiva mediante la radio, desde el 2006 existe presión periodística para que se legalicen, lo que sería un muy buen ejemplo ante la cantidad de emisoras de radio que funcionan sin licencia. El trámite para la legalización de estas emisoras se ha iniciado, pero el problema de fondo radica en el Perú carece de un modelo de radiodifusión pública o estatal, resultando este un grave vacío legal.

\section{Algunas reflexiones sobre los complejos caminos de la radio peruana}

- La ausencia de lo público genera varias de las complejidades en la radiodifusión peruana. De un lado está la modalidad de la radio educativa que ha asumido parte del rol histórico que han cumplido -y lo siguen haciendo- las radios públicas en otras partes del mundo, promoviendo la actoría social de la audiencia en tanto ciudadanos, tratando de producir programas radiales de calidad y apuesta cultural más que la búsqueda simple de gran cantidad de oyentes que representen un elevado rating, lo que facilita la venta publicitaria. Las emisoras estatales (incluso las llamadas "radios municipales") muestran una deformada función que se resume en muchos casos en la defensa del gobierno de turno (sea local o nacional). La necesidad de definir un modelo de radiodifusión pública se hace urgente. Además, será necesario promover de manera equitativa los modelos existentes.

- Democracia desde lo comunitario.Haber aprobado de forma legal la modalidad de radiodifusión comunitaria es un reconocimiento importante en un país multicultural, pero no otorgar licencias de esa modalidad es una deuda que se tiene al país diverso y con notorias necesidades de expresión y diálogo, cuestión que facilitan los medios de comunicación en su función intermediadora. Además, la multiculturalidad peruana espera que se otorguen mínimas facilidades para formalizar las radios comunitarias y que estas cuenten, como en otros países, con planes de fortalecimiento que aseguren una amplia e irrestricta libertad de expresión.

- Realidad discrecional y enforcement legal urgente.- Como hemos visto, el complejo panorama de la radio peruana se debe en parte también a la debilidad de la aplicación del marco legal. No es posible que se cierren muchas radios comerciales y de carácter comunitario por no tener licencia, es decir ser ilegales (comúnmente conocidos como "piratas") mientras desde el Estado no se cumplen todas las reglas. Las correcciones se han empezado a 
dar, pero faltan aún implementarse con mayor profundidad, por ejemplo, el Plan Nacional de Frecuencias, documento indispensable para iniciar el trámite de un permiso legal. Este debe ser actualizado en todos los ámbitos donde se solicita el establecimiento de una estación de radio; no hacerlo significaría atentar contra la libertad de expresión.

- Lo diverso como riqueza, la pugna por la comunicación y la multiculturalidad peruana.- Son características de un país que hace de la comunicación masiva -en este caso radialun escenario diverso, que además puede ayudar a sostener y fortalecer la democracia desde la libertad de expresión. En las últimas líneas no hemos abordado de manera frontal el tema de la falta de legalidad de muchas experiencias de radio, o las razones por las que existen "radios piratas"; este queda como un tema pendiente. Lo que el escenario radiofónico peruano muestra es una pugna por expresión no solo de opiniones, informaciones o voces diversas, sino también de expresiones culturales múltiples, que configuran un escenario de estética sonora muy complejo y sumamente rico. El Perú también se puede conocer escuchando radio.

- Abundancia de experiencias = múltiples oportunidades.- Para los estudiantes y jóvenes profesionales de la comunicación, que tienen en la radio un medio con menos figuración que los audiovisuales, pero de gran incidencia social, y que juegan un importantísimo rol en un país como el Perú, con una educación que debe ser apoyada de todas las formas y con un proceso democrático que puede ser fortalecido desde una responsable práctica de libertad de expresión desde la radio.

Explorar, conocer y estudiar más, es lo que falta para conocer con mayor detalle nuestra realidad social, cultural y política que también desde la radio se explica y se escucha. Sean estas líneas útiles para animar a muchos a realizar estudios e investigaciones sobre la radio y los medios masivos de comunicación en general, que nos permitan conocerlos de manera más sistemática y amplia, con el fin de discutir políticas que contribuyan al proceso de desarrollo del país y para que conociendo más produzcamos mejores emisoras de radio. 